\title{
Expectations about Fertility and Field of Study among Adolescents: A Case of Self-selection?
}

\author{
Micha G. Keijer, Aart C. Liefbroer, Ineke Nagel
}

\begin{abstract}
In recent studies on the association between education and fertility, increased attention has been paid to the field of study. Women who studied in traditionally more "feminine" fields, like care, teaching, and health, were found to have their children earlier and to have more children than other women. A point of debate in this literature is on the causal direction of this relationship. Does the field of study change the attitudes towards family formation, or do young adults with stronger family-life attitudes self-select into educational fields that emphasize care, teaching, and health? Or do both field of study preferences and family-life attitudes arise before actual choices in these domains are made?
\end{abstract}

We contribute to this debate by examining the relationship between fertility expectations and expected fields of study and occupation among 14-17 year-old adolescents. We use data collected in 2005 from 1500 Dutch adolescents and Structural Equation Modelling (SEM) to examine the associations between expected field of study and occupation and fertility expectations. Our results show that expectations concerning fertility and field of study are already interrelated during secondary education. Both female and male adolescents who expect to pursue studies in fields that focus on care and social interaction (like health care, teaching etc.) are less likely to expect to remain childless. This holds equally for girls and boys. In addition, girls who more strongly aspire to an occupation in which communication skills are important also expect to have more children. We did not find any relationship between expectations of pursuing a communicative field of study and occupation and expectations of earlier parenthood.

In addition, among boys, we find that the greater their expectation of opting for an economics, a technical, or a communicative field of study, the less likely they were to expect to remain childless. Boys who expected to study in the economic field also expect to have their first child earlier, but boys expecting to pursue a technical course of studies expect to enter parenthood later. We also found that those who expect to pursue cultural studies are more likely to have a preference for no children, or if they do want children, to have them later in life.

Overall, our findings suggest that the processes of elective affinity between the communicative fields of study and work on the one hand and fertility on the other 
hand are more or less comparable for boys and girls. With respect to the other domains, we find, apart from the gender differences in the relation between fields of study and childlessness, hardly or no gender differences in the expected timing of parenthood and the number of children. The genders do differ in their level of preference for communicative and economics-related fields of study and occupation, but if they do have the same preference, the association with fertility expectations is more or less similar.

Keywords: Education · Fertility · Field of study · Adolescent expectations

\section{Introduction}

Educational attainment is generally viewed as one of the key factors explaining late and low fertility (Blossfeld/Huinink 1991; Kohler et al. 2006; Wood et al. 2014). In the past decade, the attention of research on the impact of education on fertility has shifted in some cases from the level of education to the educational field. The field of study chosen by young adults is thought to influence their future labour market options and thus their opportunities to combine employment and family life. Women employed in sectors where it is relatively easy to combine employment and family life are likely to have more children and have them earlier than women employed in sectors where it is difficult to combine these roles. Both country-specific (Lappegard/Rønsen 2005; Hoem et al. 2006 a/b; Begall/Mills 2012; Oppermann 2014) and comparative studies (Van Bavel 2010) have provided evidence for the existence of a relationship between educational and occupational fields and fertility behaviour. Generally, these studies show earlier and higher fertility among women who have specialised in educational fields that prepare for traditionally "feminine" occupational domains, such as caring, teaching, and health than among women who have studied in another educational field (e.g. Bagavos 2010; Lappegard 2002; Begall/Mills 2012; Oppermann 2014; Tesching 2012).

Two mechanisms have been proposed to explain the relationship between field of study and fertility: field-specific socialisation and self-selection. Field-specific socialisation implies that enrolment in specific fields of study influences students' family-related attitudes. With respect to fertility, educational fields that emphasize "female qualities" lead women to develop attitudes in favour of becoming a mother early in life and having relatively large numbers of children (Van Bave/ 2010). Selfselection assumes that girls who have strong preferences for family life would "selfselect" into fields of (tertiary) education that emphasize traditionally female qualities like care or teaching (Hakim 2003). The key difference between those two explanations is that the field-specific socialisation argument suggests a causal influence of the field of education on subsequent fertility decisions, whereas according to the self-selection argument, the causal relationship is reversed, with fertility preferences shaping adolescents' choices concerning the fields of education in which they want to study and the sectors in which they seek employment. A more nuanced ver- 
sion of the self-selection argument is that preferences and choices in these two life domains develop in tandem and that there is no clear causal relationship between the two. Therefore, both processes have been modelled simultaneously (Hoem et al. 2006a/b; Martín-García/Baizán 2006; Tesching 2012; Lutz 2014). Nevertheless, little is known about the potential role of self-selection as this would require data on fertility attitudes prior to enrolment in a specific field of study (Begall/Mills 2012; Oppermann 2014). Data on expectations about prospective fields of study, occupation and fertility among adolescents would provide more information on whether expectations about educational and occupational fields on the one hand and fertility on the other hand are already aligned in adolescence, which can be regarded as indicative of self-selection processes. For this reason, we use data from adolescents (14-17 years old) to examine whether the association between expectations about future fields of study and occupation on the one hand and future fertility on the other is already present before choices have been made in these domains. Therefore, the first research question is How are adolescents' expectations concerning fertility related to their expected fields of education and occupation?

Almost all studies on the association between field of study and occupation and fertility, with the exception of Martín-García (2009) and Oppermann (2014), focus on women. Martín-García (2009) found that, contrary to women, men who pursued health and care-related studies did not have a child at an earlier age than men who studied in other fields. Opperman (2014) found no association between field of study and fertility behaviour among men in Germany. Yet men also develop expectations about fertility and employment in adolescence and this relationship might differ from that of women. Boys are also subject to gender socialisation and might develop different expectations of their role in family formation than girls (Guetto) Panichella 2013). Therefore, our second research question is To what extent do gender differences exist in the relationship between adolescents' expectations concerning fertility and their expected fields of education and occupation? To answer our questions, we use data from more than 1,500 Dutch adolescents aged 14 to 17 who were surveyed in 2005 on their plans for the future, life-course expectations and ambitions. The combination of information on future plans for fertility, education and occupation is unique. Furthermore, these respondents, who were surveyed in 2005, are currently (2019) in the prime ages in which they actually make decisions on whether and when to have children, and if so, how many.

\section{Theory}

The emergence of females' preferences concerning professional career and family life

One reason to expect that expectations concerning fertility on the one hand and educational and occupational fields on the other hand develop early in life is that both sets of expectations are shaped by interactions during childhood and adolescence with family and friends (Youniss/Smollar 1985). 
The family in which one is raised is viewed as the most important socialising institution which shapes an adolescent. Many empirical studies have shown that parental education and occupation affect children's field of study via a process of intergenerational transmission. These studies find that children's field of study strongly resembles the occupational field of the parents (Goyette 2008; Van der Werfhorst/Luijkx 2010). Another set of studies, drawing on cultural reproduction theory (Bourdieu 1986), emphasize the role of more general preferences. Bourdieu argued that the parental (cultural) environment is important in choosing a field of study, since children's choices reflect standards and practices within the social "field" in which one is raised.

The parental home is also known to influence people's fertility behaviour (Thornton 1980). The similarity between parents' and children's fertility patterns is often explained by the transmission of values and preferences from parents to children (Barber 2000). Axinn et al. (1994) find that parents' fertility values and preferences to a certain extent influence their daughters' fertility timing and quantum. Other studies found evidence for observational learning. For instance, Murphy and Wang (2001) show that coming from a large family increases the likelihood of children having a large family themselves.

Based on these processes, expectations concerning both family and career can be assumed to crystallise during adolescence. However, at least two different arguments can be put forward which suggest that this crystallisation process leads to associations between specific types of educational and occupational expectations and specific types of fertility expectations. The first argument for their interconnectedness is based on gender role theory (Stockard 2006; Risman/Davis 2013), the second one on ideas about the development of personality and social orientation among adolescents (Woods et al. 2016; Tavares 2016). We will discuss both arguments in turn.

Stockard (2006) provides an overview of the different theoretical approaches in which socialisation processes lead to the development of gendered identities that influence how girls (and boys) reflect upon their roles in key life domains relating to work and family. Charles and Bradley (2009) argue that the persistence of gender differences in the choice of educational and occupational fields is due to gender as a critical part of self-expression and identity, even in modern societies. However, the actual expression of the gender identity of girls may vary substantially, as is suggested in Hakim's "preference theory" (Hakim 2000, 2003), that offers an explanation for the way women combine family life and employment in contemporary societies. Hakim (2003) differentiates between three types of identity that are largely shaped during adolescence. First, some women consider family life and children to be their main priority and reduce their employment time to the minimum. A second category of women prioritises work over family life, and these women devote much of their life to work. The majority of women, however, try to balance work and family. Hakim (2000) labels these women as adaptive because they have no prevailing preference orientation. If girls develop a preference for such an "adaptive" lifestyle during adolescence, it is likely that they will expect to combine having children and employment. This could lead to the development of an expectation to opt for fields 
of education and fields of occupation that offer good opportunities for combining both roles. This will favour the development of expectations for studies in fields like care, health and teaching that can relatively easily be performed on a part-time basis. $^{1}$

Another explanation for the joint development of expectations concerning occupational and fertility goals in adolescence can be found in the literature on personality development. Personality characteristics have been found to be related to fertility outcomes (Jokela 2012; Skirbekk/Blekesaune 2014; Tavares 2016), choice of educational field (Korpershoek et al. 2010), and occupational choices (Wells et al. 2016; Woods et al. 2016). A high score on agreeableness, for instance, is related to a higher propensity to have children (Jokela 2012; Tavares 2016, but not Skirbekk/ Blekesaune 2012), a low propensity to opt for educational tracks in science and economics (Korpershoek et al. 2010) and a lower propensity to opt for managerialtype occupations (Wells et al. 2016) and a higher propensity to opt for health care specialties that emphasize social interaction (Woods et al. 2016). Thus, adolescent girls who score high on agreeableness might be expected to be strongly oriented towards care and social interaction, and thus to be attracted both to caring for children and to fields of study and occupation in which care and social interaction are central.

Based on these theoretical ideas, we expect that, even in adolescence, expectations about the field of study and occupation are related to fertility expectations. This implies that the association between expected field of study and expected fertility is, at least partly, already present before entering tertiary education. The development of expectations in the fields of education and occupation on the one hand and in the field of fertility on the other hand could be considered as intertwined, as it is not clear if adolescents opt for a field of study because it accommodates their fertility preference or vice versa. Therefore, we view their relationship during adolescence as essentially interdependent rather than causal, and formulate the following three hypotheses:

H1a: The greater the preference among female adolescents for fields of study and occupation in care, teaching, and health, the less likely they are to expect to remain childless.

H1b: The greater the preference among female adolescents for fields of study and occupation in care, teaching, and health, the earlier they expect to have children.

H1c: The greater the preference among female adolescents for fields of study and occupation in care, teaching, and health, the more children they expect to have.

To our knowledge, only one study has examined this relationship as yet (Kanji) Hupka-Brunner 2015). They analysed data of Swiss female adolescents at age 16/17

1 In 2017 of all jobs in the Netherlands, those in health care and teaching have a relatively low number of working hours [https://opendata.cbs.nl/statline/\#/CBS/nl/dataset/81433NED/ table?dl=12C3E, consulted October 18, 2018] 
and at age 23. Their results showed that a strong preference for children (which they termed "Kinderwunsch" (p. 125)) at age 16 made it more likely for young women to enter highly gender-segregated occupations at age 23 than their female peers with a weak preference for children. Women who had a strong preference for children and who were not in employment by the age of 23 were also more likely to be enrolled in fields of education which prepare for occupations with higher proportions of women. Thus, their results clearly support the view that the association between field of study and fertility develops early in life. However, Kanji and Hupka-Brunner (2015) used rather crude measures of fertility preference and expected occupation. They asked adolescents if they expected having children to be very important in their future life, and asked for no further information on timing and quantum preferences. Furthermore, information on fields of study and occupation was only ascertained at age 23 .

\section{Male preferences}

While most research on the association between fertility and field of study has focused on women (exceptions: Martín-Garcia 2009; Opperman 2014, 2017), we examine the relationship between expectations concerning fertility and field of study among both female and male adolescents. Are associations between expected fertility and expected field of study and occupation different for male and female adolescents? Two diametrically opposed points of view can be put forward.

On the one hand, one could argue that, if personality and social orientation are important, boys and girls will show the same level of association. Boys with an interest in caring for others and socialisation of the younger generation are more likely to choose to study in the field of care, health and teaching. On the other hand, one could also argue that preferences for traditionally male occupations among male adolescents, such as in technical and analytical fields (Davies/Guppy 1997), are an expression of their male identity (Charles/Bradley 2009). These fields usually lead to jobs with a (higher) stable income and good job security which increase the prospects of men in the partner market (Kalmijn 1998). In addition, male earning potential and fertility are often correlated within the traditional breadwinner model (Pascall 2006). According to the patriarchal norm, the breadwinner is a male working outside the home to provide the family income. The breadwinner model suggests that male adolescents who prefer this model will combine a preference for traditionally male-dominated fields of study, like economics and technical studies, with a preference for earlier and higher fertility transitions. Although we are not completely sure which of these lines of reasoning will apply, for the sake of argument we assume that the latter reasoning will be the stronger one, and therefore formulate the following hypotheses:

H2a: The greater the preference among male adolescents for educational fields and occupations related to economics and technology, the lower their likelihood of expecting to remain childless. 
$\mathrm{H} 2 \mathrm{~b}$ : The greater the preference among male adolescents for educational fields and occupations related to economics and technology, the earlier they expect to have children.

$\mathrm{H} 2 \mathrm{c}$ : The greater the preference among male adolescents for educational fields and occupations related to economics and technology, the more children they expect to have.

\section{The Dutch case}

Our study is situated in The Netherlands. The Dutch system of secondary education is markedly stratified. Children are sorted at ages 12 and 13 into a number of vertically organised secondary education tracks, and there is relatively little movement between the tracks. First choices for specific fields of study have to be taken after two or three years in secondary education, leading to horizontal tracking of adolescents as well.

The Netherlands is an interesting setting for a study on the relationship between fertility and field of study expectations in adolescents, as the reconciliation of employment and family life remains an important issue (Lewis et al. 2008). On the one hand, the Netherlands is a country with liberal gender attitudes and levels of female labour force participation and fertility that are close to the European average. On the other hand, most women work part-time, the timing of the first birth is very late and the costs of formal child care provision are quite substantial. There is also a strong minority who feels that mothers should not work full-time if they have children under age 12 (Liefbroer et al. 2015). Thus, in the Netherlands, if men and women want children, choosing fields of education and occupation that offer good opportunities for part-time work broadens their options for realising their fertility preferences. The opportunities for part-time work are particularly numerous in the public sector (including the health and care sector) and in the service sector (Statistics Netherlands 2019a). These factors make the Dutch case interesting for examining the relationship between adolescents' expectations regarding field of study and occupation and their fertility expectations.

\section{Method}

\subsection{Sample}

The data for this study were collected in 2005 (Ganzeboom et al. 2005-2006) as part of the research project Youth and Culture (Ganzeboom/Nage/ 1998-2002) which includes several studies on students in secondary education in the Netherlands. The data were collected in 14 municipalities located throughout the Netherlands. The selected municipalities include two major cities, eight medium-sized municipalities, and four small municipalities. Within these municipalities, 69 schools were contacted, of which 60 were willing to participate in the research. All of the various levels 
of education of Dutch secondary education are represented in the sample. These levels are VMBO-B (lower vocational education), MAVO/VMBO-T (lower general secondary education), HAVO (higher general secondary education) and VWO (preuniversity education). Within each school, a sample was drawn from three classes of different level-grade combinations. This procedure resulted in 190 classes of which 148 actually participated in the project. The response rate was 87 percent at the school, and 78 percent at the class level. In each class, the students were asked to complete a survey during a regular lesson $(45-50 \mathrm{~min})$. As the data collection was part of a larger project, the classes were randomly divided into two: one half of the class was given a survey on future plans and cultural participation, the other half was asked to complete a survey on computer use. In the end, 1,544 secondary school students (49 percent males and 51 percent females) aged 14-17 (34 percent VMBO, 34 percent HAVO, 33 percent VWO) filled out the questionnaire about future life plans. Selective non-response at the student level can be assumed to be limited, as questionnaires were filled out during class time and hardly any individuals refused to cooperate.

\subsection{Measurement instruments}

\section{Fertility measurements}

Fertility expectations of adolescents were measured by asking whether they thought they were going to have children in the future, with possible answers yes or no. In our study, adolescents responding "no" are counted as expecting to remain childless. Adolescents who responded "yes" were asked at what age they expected to have a first child and how many children they expected to have. Answers to these two questions were used as indicators for expected fertility timing and quantum.

\section{Expected field of study}

Adolescents' expectations with regard to their future field of study were measured by asking: "If you are thinking about going into higher education, in which field of study do you think that will be?" A list of thirteen fields of study were offered: (1) humanities, languages, history or theology, (2) social and behavioural studies, (3) art, (4) economics, commerce, business administration, (5) law and legal services, (6) teacher training or education, (7) medical, health services, nursing, (8) personal care services, (9) agriculture, (10) mathematics or science, (11) technical \& engineering, (12) transport, and (13) public order and safety. The adolescents were asked to indicate the likelihood of each field of study on a 4-point scale $(1=$ definitely not, 2 $=$ probably not, $3=$ probably, and $4=$ definitely). Based on these scores, we computed composite scores of preference for four general fields of study (cultural, economic, communicative and technical), using a classification developed by Van der Werfhorst and Kraaykamp (2001). Various classifications are used in the literature on the relation between field of study and fertility and on sex segregation within field of study, but all differentiate between health and/or care, teaching and relational skills 
and other fields of study (Hoem et al. 2006a/b; Charles/Bradley 2009; Barone 2011; Morgan et al. 2013; Michelmore/Musick 2014). The classification of Van der Werfhorst and Kraaykamp (2001) focuses on the main type of occupation-related skills developed in a field of study and is also used by Begall and Mills (2012), MartinGarcia and Baizán (2006) and Martin-Garcia (2009). Like these authors, we adjusted the original coding scheme by deeming a preference for becoming a teacher to be communicative rather than cultural. Cultural fields of study comprise humanities, languages, history, theology, social and behavioural studies and art. Economic fields of study comprise economics, commerce, business administration, law and legal services. Communicative fields of study comprise teacher training, education, medical and health services, nursing and personal care. Technical fields of study comprise agriculture, mathematics or science, technical and engineering, transport and public order and safety. This compressed educational field categorisation gives a better view of which type of skills the adolescent wants/expects to develop in the future. A preference score for each of the four main fields of study was calculated by summing the scores of all the constituting specific fields of studies and dividing by the number of specific fields. Descriptive information on the means and standard deviations for all four expected fields of study are presented in Table 1.

\section{Aspired field of occupation}

To ascertain what kind of occupations adolescents aspired to, the following question was posed: "How much would you like to practise the following occupations?" Respondents were presented with a list of 30 different occupations. Answers were scored on a four-point scale: absolutely not, rather not, maybe and gladly. Examples of occupations that had to be scored were physician, lawyer, teacher, truck driver, and hairdresser. To compress these 30 different occupations, they were classified into five broad categories: cultural, economic, communicative, technical and lower (Van der Werfhorst/Kraaykamp 2001; Begall/Mills 2012). This classification largely mirrored the one used to classify fields of study. The category "lower" was added, as some of the occupations (for instance cleaner, assembly line worker, shop attendant, etc.) asked for few specific skills and could not easily be classified into one of the four main fields of occupation. Using the same procedure as for field of study, a composite score was calculated for the aspiration of each student with regard to each of the five fields of occupation (see Table 1 for means and standard deviations).

\section{Educational level}

Adolescents' current level in secondary school is used as a control variable in all analyses. The educational level was measured on a scale from 1 (lower vocational) to 4 (pre university). Subsequently, this level of education was recoded using the newly developed International Standard Level of Education (ISLED) scoring system (Schröder/Ganzeboom 2014). ISLED is an empirically obtained, internationally comparable interval scale for educational level, the value of which can vary between 0 and 100. 


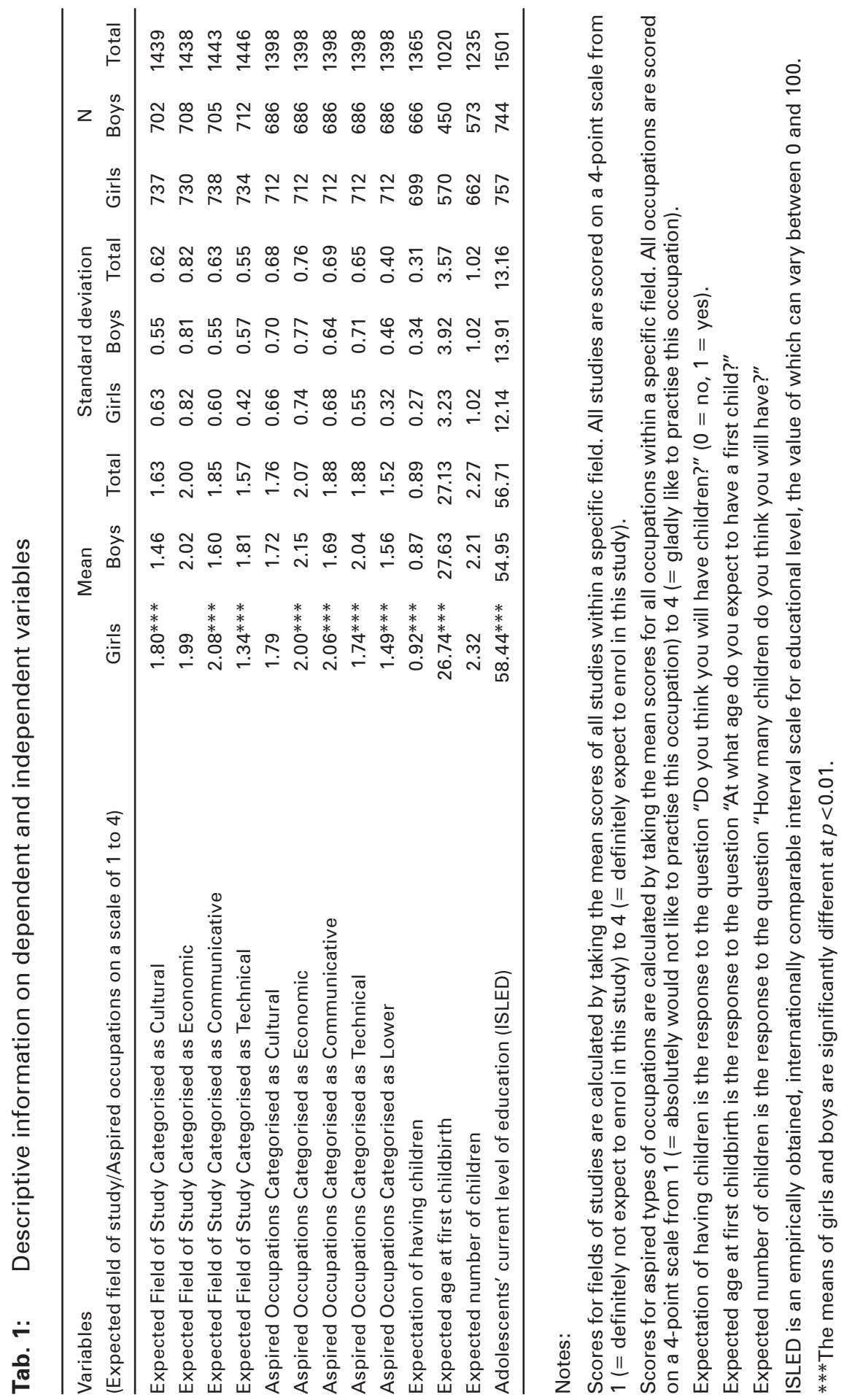




\section{Analysis Strategy}

Structural equation modelling (SEM) was used to estimate the relationships between adolescents' expected fertility on the one hand, and expected field of study and aspired occupational field on the other. To account for item non-response in the data, the models were estimated in Mplus using the "full information maximum likelihood" (FIML) method (Muthén/Muthén 2004), in which a cluster correction was applied at the level of school classes. FIML allows us to make maximum use of all the available data in our dataset. It has comparable statistical properties to multiple imputation, but is more efficient (Allison 2012). All models are evaluated using three widely-used overall goodness of fit criteria (Root Mean Square Error of Approximation [RMSEA], the Comparative Fit Index [CFI], and the Tucker-Lewis Index [TLI]). The fit of models is deemed good if RMSEA $<0.06$, and CFI and TLI $>0.95(\mathrm{Hu} /$ Bentler 1999). First, a logit model with the expectation of remaining childless as the dependent variable was estimated. Next, models with the expected timing of fertility and the expected number of children as the dependent variables were estimated simultaneously among those adolescents who expected to have children. In all analyses, the expectations regarding the educational field and aspirations regarding the occupational field were used as independent variables. In addition, we controlled for the adolescents' current level of education. To test whether the outcomes varied by gender, interaction effects were added between expectations on fertility and field of education and occupation and gender (Hardy 1993). Unstandardised parameter estimates are presented for all models in Table 2. In additional analyses (results not shown), we examined whether the results would change if we did not include the scores on "lower" aspired occupations in the models. Results for other parameters did not differ, suggesting that the results were robust with regard to the in- or exclusion of lower aspired occupations.

\section{$5 \quad$ Results}

\section{Descriptive findings}

Separately for boys and girls, Table 1 shows means, standard deviations and number of responses for the variables used in the analysis. Clear gender differences could be observed in the expectations for broad field of study. Girls had a stronger expectation to opt for communicative and cultural fields, whereas boys had a stronger expectation to opt for technical fields. No gender differences were observed for an expectation to opt for economic fields. Boys most strongly expected to opt for economic fields of study, followed by technical, communicative and cultural fields, whereas girls expected to opt for communicative, economic, cultural and technical fields, in that order. With regard to aspired occupational fields, no gender differences were observed for cultural occupations, but girls aspired to communicative jobs more than boys, and boys aspired to economic and technical jobs more than girls. Among boys, jobs in the economic field were the strongest preference, whereas 
among girls, jobs in the communicative field were the strongest preference. Concerning fertility, most adolescents expected to have children, and fewer girls (8 percent) than boys (13 percent) expected to remain childless $(t=-3.22, p<0.01)$. Girls expected that they would have their first child around age 26.7 , while boys expected this on average about a year later. The average number of children which adolescents expected to have was a little over two children, and did not differ between boys and girls. Clearly, there is a substantial gap between fertility ideals and actual fertility behaviour, because in the Netherlands in 2005 the average age of women having their first child was 29.4 years and the average number of children was 1.71 (Statistics Netherlands 2019b). This gap between "optimistic" expectations and "obstinate" reality is consistent with earlier findings within the so-called fertility gap literature (Liefbroer/Billari 2010).

\section{Expectations for educational and occupational field and for childlessness}

Next, multivariate analyses were performed to study the association between field of study and occupation and fertility expectations. The results are presented in Table 2. All models show an excellent fit based on standard goodness of fit criteria (RMSEA, CFI, TLI). Model 1 presents results for boys and girls together, whereas in Model 2, interactions between gender and educational and occupational field are included to test whether the same patterns apply to boys and girls. A logit regression was performed to examine the link between expected field of study and the expectation of remaining childless. Model 1 suggests strong associations between expected field of study and childlessness. The greater the expectation among adolescents to study in the field of communication, the more likely they were to expect to have children $(b=0.352)$. The opposite was true for expectations of pursuing cultural studies; this was associated with a lower expectation of having children $(b=-0.271)$. Only weak evidence was found for an association between aspired occupational field and expectations regarding childlessness. The greater the expectation among adolescents to work in the field of communication, the more likely they were to expect to have children $(b=0.215)$, whereas the greater their expectation to pursue a lower occupation, the less likely they were to want children $(b=-0.325)$. Clearly, preferences regarding childlessness were more strongly related to adolescents' expected field of study than to their aspired field of occupation.

Interactions between gender and the other variables in the model were included in Model 2. Several statistically significant interactions were observed. The upper half of Model 2 presents the effects for boys. The bottom half shows the estimates for the extent to which the effects for girls deviate from those for boys. First, the negative association between the expectation of entering a cultural field of study and wanting children among boys was $-0.444(p<.01)$. To calculate the estimate for girls, the estimate for the interaction variable for a cultural field of study and sex $(0.380)$ was added to the parameter for boys (-.0444), leading to an effect for girls of -0.064 . Additional analysis revealed that this parameter is not statistically significantly different to 0 . Thus, the negative association between the expectation of pursuing a cultural field of study and expecting to have children is only observed 


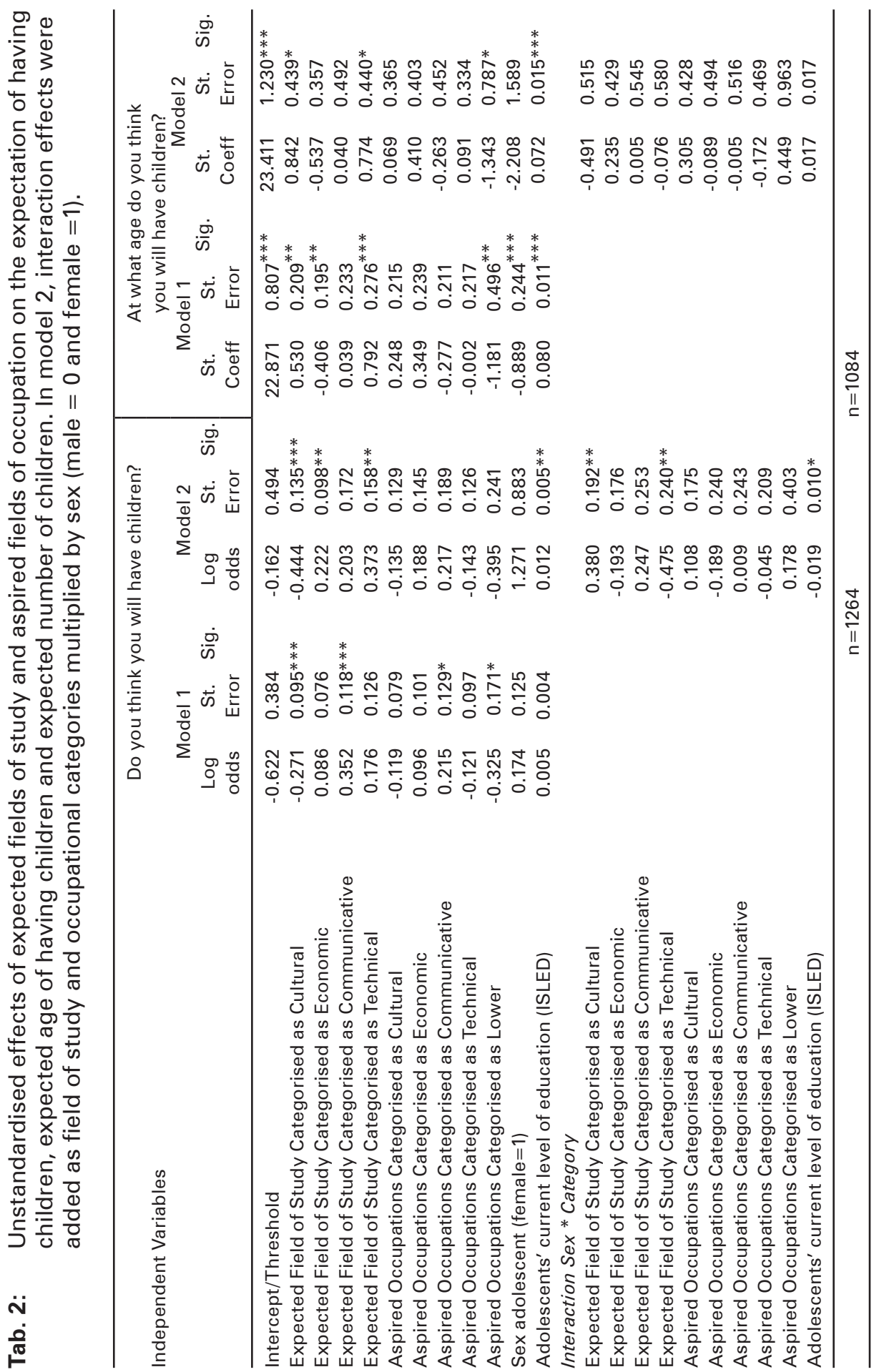




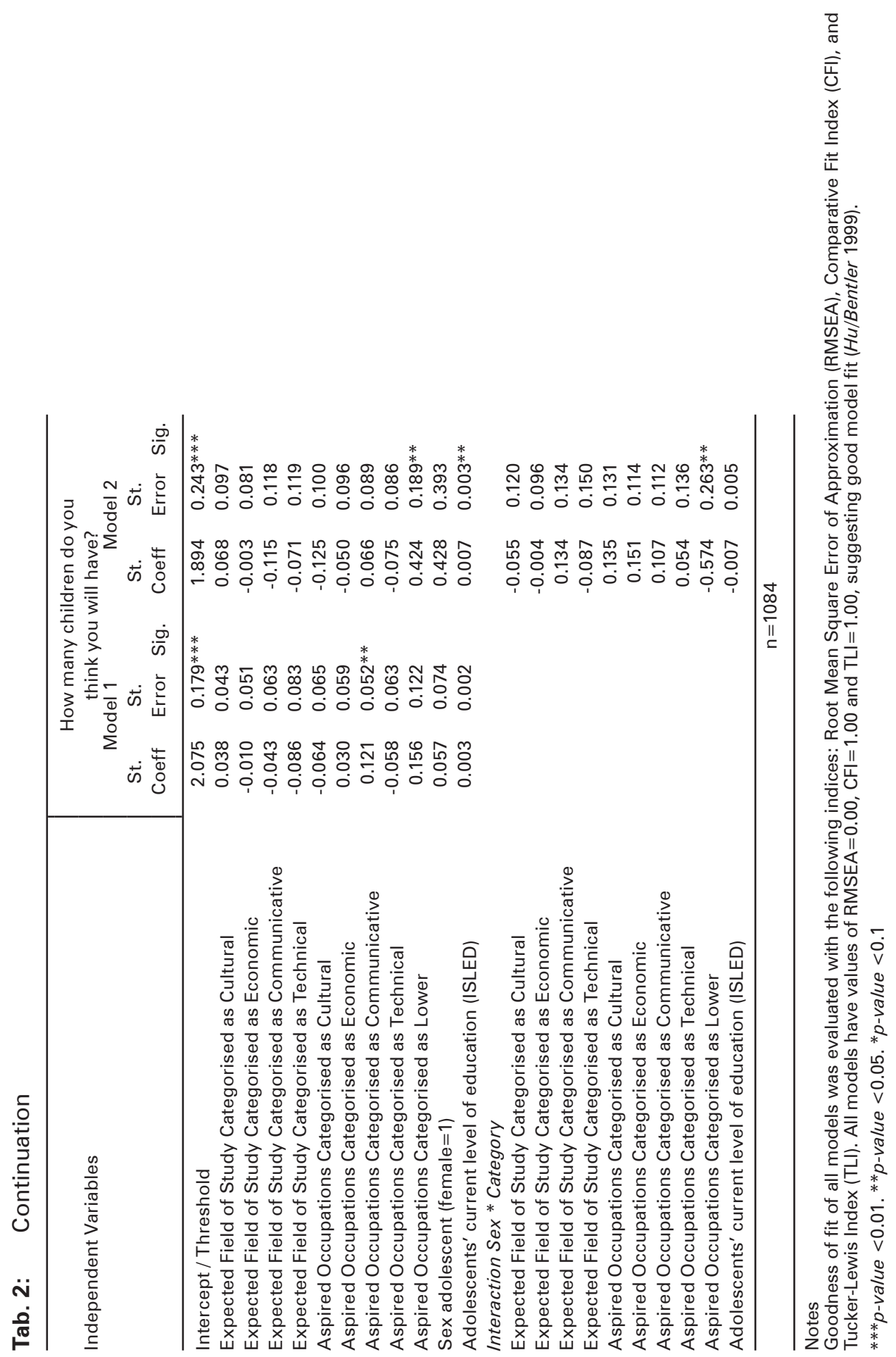


in boys, not in girls. Second, among boys, a stronger preference for having children is associated with a stronger expectation for pursuing an economic field of study $(b=0.222)$ and a stronger expectation for pursuing a technical field of study $(b=0.373)$. No such associations are found among girls $(b=0.222-0.193=0.029$, n.s.; $b=0.373-0.475=-0.102$, n.s.). Among girls, we only find a positive relationship between expectations of studying in the field of communication and the expectation of having children. The relation between expected studies in the communicative field is equally related to expected childlessness for boys and girls. Among boys, all four fields of study are related to the desire to have children. Boys with stronger expectations for studying in the cultural field are less likely to expect to have children, whereas boys with stronger expectations for studying in economic, communications and technical fields of study are more likely to want children. For girls, only an expectation of studying in the communicative field is relevant in this respect. The association between job aspiration and childlessness does not vary significantly between boys and girls.

\section{Expected educational and occupational fields and expected age of entry into parenthood}

The results in Table 2 on the expected age of entering into parenthood suggest that there are no gender differences in the underlying process (see middle panel of Table 2, Model 2). Therefore, only results from Model 1 are discussed. For both female and male adolescents, the expected age of entry into parenthood was strongly related to their current level of education and their expected field of education. The higher the adolescents' current level of education, the later their expected age of having children $(b=0.080)$. Stronger expectations of studying in cultural and technical fields were associated with a higher expected age of entry into parenthood ( $b=0.530$ and $b=0.792$, respectively). Stronger expectations for studying in the field of economics was associated with a lower expected age of entry into parenthood $(b=-0.406)$. No association was found between the expectation of studying in the communications field and expected age of entry into parenthood. No associations were found between aspired occupational fields and expected age of entry into parenthood either, with one exception: boys and girls who "aspired" to a lower type of occupation expected to have their first child earlier $(p<0.05)$.

\section{Expected educational and occupational field and expected number of children}

The final panel of Table 2 shows the results for the association between educational and occupational field and the number of children that adolescents expect. Only few statistically significant associations were observed. Model 1 shows that the more strongly adolescents aspired to an occupation in communication, the more children they expected to have $(b=0.121)$. Model 2 shows that boys and girls who "aspire" to a lower type of occupation differ in their views on the number of children they expect. Among boys, a stronger aspiration for a lower type of occupation is associ- 
ated with a higher expected number of children $(b=0.424)$, whereas no association is found among girls $(b=0.424-0.574=-0.150, n s)$.

\section{Conclusion}

The growing literature on the association between fertility, field of study and occupation shows that fertility is higher among women who were educated or are employed in communicative fields that emphasize teaching and care. An unresolved issue in the literature is to what extent field-specific/occupational socialisation processes influence fertility decisions of young adults, or to what extent young adults are selected into specific fields of study and occupation because of pre-existing preferences concerning family life and employment. The goal of this study was to examine if such a selection effect is likely. We did so by studying the associations between adolescents' expectations and preferences concerning fertility, field of study and occupation during the life phase before entering tertiary education. In addition to studying this relationship among adolescent girls, we also examined it among boys.

Our first set of hypotheses stated that girls that expect to enter communicative educational and occupational fields were also less likely to remain childless and had a greater likelihood of having more children and having them earlier. Several findings are in line with this hypothesis. The greater the expectation among girls to opt for communicative fields of study, the more likely they are to have children. In addition, the more likely girls are to prefer jobs in the communicative field, the more children they expect to have. Thus, there seems to be an elective affinity between preferences for studies and jobs that emphasize caring and social interaction and fertility expectations among adolescent girls. The expected timing of having children is not associated with expectations of pursuing a communicative field of study or aspired occupation. What is striking, though, is that this elective affinity also applies to boys. Here, too, a preference for studies and jobs that emphasize care and social interaction goes hand in hand with stronger fertility preferences. Rather than showing gender-specific patterns, as has been suggested by earlier studies (e.g. Van Bave/ 2010; Hakim 2003), both girls and boys who are attracted to studies and jobs in the social domain are also attracted to parenthood. Clearly, girls are more likely to feel attracted to studies and jobs in the social domain, but boys who feel drawn to these studies show the same pattern of associations as girls.

The second set of hypotheses stated that boys that expect to opt for studies and jobs in the economic and technical domain are more likely to expect to have children, to have more children and to have them earlier. The results only partially confirmed our hypotheses about this link. The greater the expectation among male adolescents to opt for an economic field of study, the less likely they were to expect to remain childless and the more likely they were to have their first child somewhat earlier. Boys who preferred technical fields of study and occupation were also less likely to expect to remain childless, but they expected to have children at a later age, which is not in line with the hypothesis. On top of this, similar associations be- 
tween expected field of study and expected timing of entry into parenthood and the expected number of children were observed among both boys and girls, again suggesting that the processes of elective affinity between domain of study and work on the one hand and fertility on the other hand are more or less comparable for boys and girls. The genders differ in their likelihood of preferring communicative and economic fields of study and occupation, but if they do have the same preference, the association with fertility expectations is more or less the same.

A result we did not anticipate is that the greater the expectation among male adolescents to opt for cultural studies, the more likely it was that they expected to remain childless and, if they did expect to have children, to have them later in life. This latter result is congruent with Van Bavel's (2010) finding in the Netherlands that people who are trained in arts and the humanities are the most progressive concerning family attitudes. It shows that adolescents opting for these fields of study and occupations have significantly different fertility values, suggesting that men with more "traditional/conservative" values are different from men with "artistic/ progressive" values.

Our results clearly show that expectations regarding field of study and occupation and fertility are already related to each other during the teenage years and this strongly suggests that the association between field of education and actual fertility found among adults is indeed at least partially the result of processes of selfselection occurring at an early stage in the life course. Our study could not examine which mechanisms "cause" the association between field of study and fertility preferences among adolescence: for instance whether it reflects gendered identities, as suggested by Charles and Bradley (2009), or to what extent these are in turn the result of common causes like early socialisation or personality. Future research could, for instance, examine the role of parental (gender) socialisation, personality traits (Jokela 2012), and other background variables, such as socioeconomic status or religiosity of the parents (Hubert 2014), or the role of schools and peers (Driscoll) Abma 2015).

The cross-sectional nature of our study did not allow us to study how realistic adolescents' expectations are. Using panel data, it would be interesting to examine to what extent adolescents' expectations are realised, and whether the same processes influence both their expectations and their actual behaviour. In addition, panel data would allow us to study the consistency and development of preferences regarding fertility, field of study and occupation. Such a design would be particularly interesting given that it allows the direct disentanglement of causality and self-selection in the relationship between fertility and educational and occupational field, and identification of common causes, e.g. early socialisation and personality traits, that could explain both types of preferences. Finally, in line with research on country variation in the association between actual choices in fertility and fields of study (Van Bave/ 2010; Oppermann 2017), it would be interesting to study country variations in the association between preferences in the professional and the family domain. The degree to which educational systems and labour markets allow for the expression of gendered identities, which was found to be related to gender segregation in fields of study (Charles/Bradley 2009), differs between countries. It 
could therefore be expected that a stronger correlation between preferences in the professional and the family domain will be found in countries that allow stronger expression of such gendered identities. In addition, institutional arrangements like maternity leave, possibilities to work part-time, social acceptance etc. also differ per society. It would be interesting to examine whether countries that facilitate "working-mothers" and "caring fathers" are more likely to exhibit a weaker relation between preferences regarding fertility, field of study and occupation.

\section{References}

Allison, Paul D. 2012: Handling missing data by maximum likelihood. Paper presented at the SAS Global Forum (paper 312-2012) [http://www.statisticalhorizons.com/wpcontent/uploads/MissingDataByML.pdf, 22.07.2019].

Axinn, William G.; Clarkberg, Marin, E.; Thornton, Arland 1994: Family influences on family size preferences. In: Demography 31,1: 65-79 ]doi: 10.2307/2061908].

Bagavos, Christos 2010: Education and childlessness: the relationship between educational field, educational level, employment and childlessness among Greek women born in 1955-1959. In: Vienna Yearbook of Population Research 8: $51-75$ [doi: 10.1553/ populationyearbook2010s51].

Barber, Jennifer S. 2000: Intergenerational influences on the entry into parenthood: mothers' preferences for family and non-family behavior. In: Social Forces 79,1: 319348 [doi: 10.1093/sf/79.1.319].

Barone, Carlo 2011: Some things never change: Gender segregation in higher education across eight nations and three decades. In: Sociology of Education 84,2: 157-176 [doi: 10.1177/0038040711402099].

Van Bavel, Jan 2010: Choice of study discipline and the postponement of motherhood in Europe: The impact of expected earnings, gender composition, and family attitudes. In: Demography 47,2: 439-458 [doi: 10.1353/dem.0.0108].

Begall, Katia; Mills, Melinda C. 2012: The influence of educational field, occupation, and occupational sex segregation on fertility in the Netherlands. In: European Sociological Review 29,4: 720-742 [doi: 10.1093/esr/jcs051].

Blossfeld, Hans Peter; Huinink, Johannes 1991: Human capital investments or norms of role transition? How women's schooling and career affect the process of family formation. In: American Journal of Sociology 97,1: 143-168.

Bourdieu, Pierre 1986: The forms of capital. In: Biggart, Nicole Woolsey (Ed.): Readings in Economic Sociology. Oxford: Blackwell Publishers: 280-291 [doi: 10.1002/9780470755679.ch15].

Bozick, Robert et al. 2010: Framing the future: Revisiting the place of educational expectations in status attainment. In: Social Forces 88,5: 2027-2052 [doi: 10.1353/ sof.2010.0033].

Charles, Maria; Bradley, Karen 2009: Indulging our gendered selves? Sex segregation by field of study in 44 countries. In: American Journal of Sociology 114,4: 924-976 [doi: 10.1086/595942].

Davies, Scott; Guppy, Neil 1997: Fields of study, college selectivity, and student inequalities in higher education. In: Social Forces 75,4: 1417-1438 [doi: 10.1093/sf/75.4.1417]. 
Driscoll, Anne K.; Abma, Joyce C. 2015: Changing sociodemographic factors and teen fertility: 1991-2009. In: Maternal and Child Health Journal 19,10: 2159-2167 [doi: 10.1007/s10995-015-1728-8].

Ganzeboom, Harry B.G.; Nagel, Ineke 1998-2002: Youth and culture. A multi-actor panel study (machine readable datafiles). Utrecht: Interuniversity Center for Social Science Theory and Methodology. Available from the authors.

Ganzeboom, Harry B.G.; Nagel, Ineke; Liefbroer, Aart C. 2005-2006: Youth and culture. A multi-actor panel study. Cultural participation and future plans (machine readable datafiles). Amsterdam: Vrije Universiteit. Available from the authors.

Goyette, Kimberly A. 2008: College for some to college for all: Social background, occupational expectations, and educational expectations over time. In: Social Science Research 37,2: 461-484 [doi: 10.1016/j.ssresearch.2008.02.002].

Guetto, Raffaele; Panichella, Nazareno 2013: Geographical mobility and reproductive choices of Italian men. In: European Sociological Review 29,2: 302-315 [doi: 10.1093/ esr/jcr068].

Hakim, Catherine 2000: Work-Lifestyle Choices in the 21st Century: Preference Theory. Oxford: Oxford University Press.

Hakim, Catherine 2003: A new approach to explaining fertility patterns: Preference theory. In: Population and Development Review 29,3: 349-374.

Hardy, Melissa A. 1993: Regression with Dummy Variables. Newbury Park, Cal.: Sage [doi: 10.4135/9781412985628].

Hoem, Jan M.; Neyer, Gerda; Andersson, Gunnar 2006a: Educational attainment and ultimate fertility among Swedish women born in 1955-59. In: Demographic Research 14,16: 381-404 [doi: 10.4054/DemRes.2006.14.16].

Hoem, Jan M.; Neyer, Gerda; Andersson, Gunnar 2006b: Education and childlessness: The relationship between educational field, educational level, and childlessness among Swedish women born in 1955-59. In: Demographic Research 14,15: 331-380 [doi: 10.4054/DemRes.2006.14.15].

Hu, Li-tze; Bentler, Peter M. 1999: Cutoff criteria for fit indexes in covariance structure analysis: Conventional criteria versus new alternatives. In: Structural Equation Modeling: A Multidisciplinary Journal 6,1: 1-55 [doi: 10.1080/10705519909540118].

Hubert, Sandra 2014: The Impact of Religiosity on Fertility: A Comparative Analysis of France, Hungary, Norway, and Germany. Wiesbaden: Springer [doi: 10.1007/978-3658-07008-3].

Jokela, Markus 2012: Birth-cohort effects in the association between personality and fertility. In: Psychological Science 23,8: 835-841 [doi: 10.1177/0956797612439067].

Kalmijn, Matthijs 1998: Intermarriage and homogamy: Causes, patterns, trends. In: Annual Review of Sociology 24: 395-421 [doi: 10.1146/annurev.soc.24.1.395].

Kanji, Shireen; Hupka-Brunner, Sandra 2015: Young women's strong preference for children and subsequent occupational gender segregation: What is the link? In: Equality, Diversity and Inclusion: An International Journal 34,2: 124-140 [doi: 10.1108/EDI-052014-0041].

Kohler, Hans-Peter; Billari, Francesco C.; Ortega, José Antonio 2006: Low fertility in Europe: Causes, implications and policy options. In: Harris, Fred R. (Ed.): The Baby Bust: Who Will Do the Work? Who Will Pay the Taxes? Lanham, ML: Rowman \& Littlefield Publishers: 48-109. 
Korpershoek, Hanke et al. 2010: Who 'fits' the science and technology profile? Personality differences in secondary education. In: Journal of Research in Personality 44,5: 649-654 [doi: 10.1016/j.jrp.2010.08.010].

Lappegård, Trude 2002: Education Attainment and Fertility Pattern among Norwegian Women. Oslo: Statistisk Sentralbyrå.

Lappegård, Trude; Rønsen, Marit 2005: The multifaceted impact of education on entry into motherhood. In: European Journal of Population 21,1: 31-49 [doi: 10.1007/s10680004-6756-9].

Lareau, Annette 2011: Unequal Childhoods: Class, Race, and Family Life. Berkeley: University of California Press.

Lewis, Jane et al. 2008: Patterns of development in work/family reconciliation policies for parents in France, Germany, the Netherlands, and the UK in the 2000s. In: Social Politics: International Studies in Gender, State \& Society 15,3: 261-286 [doi: 10.1093/ $\mathrm{sp} / \mathrm{jxn} 016]$.

Liefbroer, Aart C.; Billari, Francesco C. 2010: Bringing norms back in: A theoretical and empirical discussion of their importance for understanding demographic behaviour. In: Population, Space and Place 16,4: 287-305 [doi: 10.1002/psp.552].

Liefbroer, Aart C.; Merz, Eva-Maria; Testa, Maria Rita 2015: Fertility-related norms across Europe: A multi-level analysis. In: Philipov, Dimiter; Liefbroer, Aart C.; Klobas, Jane E. (Eds.): Reproductive Decision-Making in a Macro-Micro Environment. New York: Springer: 141-163 [doi: 10.1007/978-94-017-9401-5_6].

Lutz, Katharina 2014: Compensating dissatisfaction in the job by turning to the family? The impact of current occupation on timing of first births in Germany. In: Advances in Life Course Research 21: 43-58 [doi: 10.1016/j.alcr.2014.03.003].

Martín-García, Teresa 2009: 'Bring men back in': a re-examination of the impact of type of education and educational enrolment on first births in Spain. In: European Sociological Review 25,2: 199-213 [doi: 10.1093/esr/jcn041].

Martín-García, Teresa; Baizán, Pau 2006: The impact of the type of education and of educational enrolment on first births. In: European Sociological Review 22,3: 259-275 [doi: 10.1093/esr/jci056].

Michelmore, Katherine; Musick, Kelly 2014: Fertility patterns of college graduates by field of study, U.S. women born 1960-79. In: Population Studies 68,3: 359-374 [doi: 10.1080/00324728.2013.847971]

Morgan, Stephen L.; Gelbgiser, Dafna; Weeden, Kim A. 2013: Feeding the pipeline: Gender, occupational plans, and college major selection. In: Social Science Research 42,4: 989-1005 [doi: 10.1016/j.ssresearch.2013.03.008].

Murphy, Michael; Wang, Duolao 2001: Family-level continuities in childbearing in lowfertility societies. In: European Journal of Population 17,1: 75-96 [doi: 10.1023/A: 1010744314362]

Muthén, Linda K.; Muthén, Bengt O. 2004: Mplus: The comprehensive modeling program for applied researchers. Los Angeles, CA: Muthén \& Muthén.

Oppermann, Anja 2014: Exploring the relationship between educational field and transition to parenthood - An analysis of women and men in Western Germany. In: European Sociological Review 30,6: 728-749 [doi: 10.1093/esr/jcu070].

Oppermann, Anja 2017: Educational field and fertility in western Germany: An analysis of women born between 1955 and 1959. In: Vienna Yearbook of Population Research 15: 239-267 [doi: 10.1553/populationyearbook2017s239]. 
Pascall, Gillian 2010: Male breadwinner model. In: Fitzpatrick, Tony et al. (Eds.): International Encyclopedia of Social Policy. 1st ed. London/New York: Routledge.

Risman, Barbara J.; Davis, Georgiann 2013: From sex roles to gender structure. In: Current Sociology 61,5-6: 733-755 [doi: 10.1177/0011392113479315].

Rønsen, Marit; Skrede, Kari 2010: Can public policies sustain fertility in the Nordic countries? Lessons from the past and questions for the future. In: Demographic Research 22,13: 321-346 [doi: 10.4054/DemRes.2010.22.13].

Schröder, Heike; Ganzeboom, Harry B.G. 2014: Measuring and Modelling Level of Education in European Societies. In: European Sociological Review 30,1: 119-136 [doi: 10.1093/esr/jct026].

Skirbekk, Vegard; Blekesaune, Morten 2014: Personality traits increasingly important for male fertility: Evidence from Norway. In: European Journal of Personality 28,6: 521 529 [doi: 10.1002/per.1936].

Statistics Netherlands 2019: Information on Employment by Sector [https://opendata. cbs.nl/statline/\#/CBS/nl/dataset/81432ned/table?ts=1559038555556, 28.05.2019].

Statistics Netherlands 2019b: Information on Births [https://opendata.cbs.nl/statline/\#/ $\mathrm{CBS} / \mathrm{nl} /$ dataset$/ 37422 \mathrm{ned} / \mathrm{table}$ ?ts $=1559039903598,28.05 .2019]$.

Steenhof, Liesbeth; Liefbroer, Aart C. 2008: Intergenerational transmission of age at first birth in the Netherlands for birth cohorts born between 1935 and 1984: Evidence from municipal registers. In: Population Studies 62,1: 69-84 [doi: 10.1080/00324720701788616].

Stockard, Jean 2006: Gender socialization. In: Saltzman Chafetz, Janet (Ed.): Handbook of the Sociology of Gender. New York: Springer: 215-227 [doi: 10.1007/0-387-362185_11].

Tavares, Lara Patrício 2016: Who delays childbearing? The associations between time to first birth, personality traits and education. In: European Journal of Population 32,4: 575-597 [doi: 10.1007/s10680-016-9393-1].

Tesching, Karin 2012: Education and Fertility. Dynamic Interrelations Between Women's Educational Level, Educational Field and Fertility in Sweden. Acta Universitatis Stockholmiensis: Stockholm University Demography Unit - Dissertation Series 6 [URN: urn:nbn:se:su:diva-63761].

Thornton, Arland 1980: The influence of first generation fertility and economic status on second generation fertility. In: Population and Environment 3,1: $51-72$ [doi: 10.1007/ BF01253070].

Trent, Katherine; Crowder, Kyle 1997: Adolescent birth intentions, social disadvantage, and behavioral outcomes. In: Journal of Marriage and Family 59,3: 523-535 [doi: 10.2307/353943]

Wells, Robert; Ham, Roger; Junankar, P.N. 2016: An examination of personality in occupational outcomes: antagonistic managers, careless workers and extraverted salespeople. In: Applied Economics 48,7: 636-651 [doi: 10.1080/00036846.2015.1085636].

Van de Werfhorst, Herman G.; Kraaykamp, Gerbert 2001: Four field-related educational resources and their impact on labor, consumption and sociopolitical orientation. In: Sociology of Education 74,4: 296-317 [doi: 10.2307/2673137].

Van de Werfhorst, Herman G.; Luijkx, Ruud 2010: Educational field of study and social mobility: Disaggregating social origin and education. In: Sociology 44,4: 695-715 [doi: 10.1177/0038038510369362]. 
Wood, Jonas; Neels, Karel; Kil, Tine 2014: The educational gradient of childlessness and cohort parity progression in 14 low fertility countries. In: Demographic Research 31,46: 1365-1416 [doi: 10.4054/DemRes.2014.31.46].

Woods, Stephen A. et al. 2016: Personality and occupational specialty. An examination of medical specialties sing Holland's RIASEC model. In: Career Development International 21,3: 262-278 [doi: 10.1108/CDI-10-2015-0130].

Youniss, James; Smollar, Jacqueline 1985: Adolescent Relations with Mothers, Fathers, and Friends. Chicago: University of Chicago Press.

Dr. Micha G. Keijer ( $₫)$. Amsterdam University of Applied Sciences, Amsterdam School of International Business (AMSIB). Amsterdam, The Netherlands.

E-mail: m.g.keijer@hva.nl

URL: https://www.amsterdamuas.com/amsib/profile/k/e/m.g.keijer/m.g.keijer.html?orig in $=$ Z\%2B1TAmBTT1GFpljJFzuhXQ

Prof. Dr. Aart C. Liefbroer. Netherlands Interdisciplinary Demographic Institute (NIDI). The Hague, The Netherlands. E-mail: liefbroer@nidi.nl

URL: https://www.nidi.nl/en/staff/overview/liefbroer

Dr. Ineke Nagel. Vrije University Amsterdam, Faculty of Social Sciences, Sociology,

Social Inequality and the Life Course (SILC). Amsterdam, The Netherlands.

E-mail: f.a.nagel@vu.nl

URL: https://research.vu.nl/en/persons/ineke-nagel 


\section{Comparative Population Studies}

WWW.comparativepopulationstudies.de

ISSN: 1869-8980 (Print) - 1869-8999 (Internet)

\section{Published by}

Prof. Dr. Norbert F. Schneider

Federal Institute for Population Research D-65180 Wiesbaden / Germany

\section{(c) BY-SA}

2019

\section{Managing Editor \\ Prof. Philip Rees \\ Dr. Katrin Schiefer}

\section{Copy Editor}

Julia Luther

\section{Editorial Assistant}

Beatriz Feiler-Fuchs

Wiebke Hamann

\section{Layout \\ Beatriz Feiler-Fuchs \\ E-mail:cpos@bib.bund.de}

\section{Scientific Advisory Board}

Karsten Hank (Cologne)

Michaela Kreyenfeld (Berlin)

Marc Luy (Vienna)

Natalie Nitsche (Vienna)

Peter Preisendörfer (Mainz)

Zsolt Spéder (Budapest)

Rainer Wehrhahn (Kiel)

\section{Board of Reviewers}

Martin Abraham (Erlangen)

Laura Bernardi (Lausanne)

Hansjörg Bucher (Bonn)

Claudia Diehl (Konstanz)

Andreas Diekmann (Zurich)

Gabriele Doblhammer-Reiter (Rostock)

Jürgen Dorbritz (Wiesbaden)

Anette Eva Fasang (Berlin)

E.-Jürgen Flöthmann (Bielefeld)

Alexia Fürnkranz-Prskawetz (Vienna)

Beat Fux (Salzburg)

Joshua Goldstein (Berkeley)

Sonja Haug (Regensburg)

Hill Kulu (Liverpool)

Aart C. Liefbroer (The Hague)

Kurt Lüscher (Konstanz)

Emma Lundholm (Umeå)

Nadja Milewski (Rostock)

Dimiter Philipov (Vienna)

Roland Rau (Rostock)

Tomáš Sobotka (Vienna)

Jeroen Spijker (Barcelona)

Olivier Thévenon (Paris)

Helga de Valk (Brussels)

Heike Trappe (Rostock)

Michael Wagner (Cologne) 